\title{
Physical Activity, Dietary Intake and Anthropometric Indices of a Group of Nigerian University Undergraduates
}

\author{
Maruf F.A., Akosile C.O., Umunnah J.O. \\ Department of Medical Rehabilitation, College of Health Sciences and Technology, Nnamdi Azikiwe University, \\ Nnewi Campus, Nnewi, Anambra State, Nigeria
}

Correspondence

F.A. Maruf, Department of Medical Rehabilitation, College of Health Sciences and Technology, Nnamdi Azikiwe University, Nnewi Campus, Nnewi, Anambra State, Nigeria・Email:mafaad@yahoo.com

\begin{abstract}
SUMMARY
This study explores the interrelationships among the physical activity level, dietary pattern and anthropometric indices of some pre-clinical undergraduates in a university in southeastern Nigeria.

One hundred and twenty-one (121) consecutively-recruited volunteers (57 male and 64 female), aged 19-29 years, who were pre-clinical students participated in the study. Information on physical activity level (PAL), dietary pattern and anthropometric characteristics as well as demographics was collected.

About $80 \%$ of the male and female participants had normal weight. Fewer males $(11.1 \%)$ than females $(17.6 \%)$ reported low PAL. Fewer males $(5.7 \%$ and $7.7 \%)$ tended to have undesirable waist circumference (WC) and waist-hip ratio (WHR) than the females $(16.2 \%$ and $41.2 \%)$. Also fewer males $(24.1 \%)$ tended to have a high fat intake than females $(30.9 \%)$. However, more males $(87.0 \%)$ tended to take low amounts of fruit/vegetable (FV) than females $(79.4 \%)$, whereas more females $(89.75 \%)$ tended to take low amount of fibre than the males $(57.4 \%)$. The females had a higher $(\mathrm{P}<0.05)$ WHR than the males, while the males consumed more fibre $(\mathrm{P}<0.05)$ than the females. Fat intake correlated very significantly $(\mathrm{P}<0.05)$ with $\mathrm{W}$ C. Fibre intake correlated very significantly $(\mathrm{P}<0.05)$ with $\mathrm{WC}$ and $\mathrm{WHR}$, while PAL correlated significantly with only BMI and WC. Although the prevalence of general obesity is not alarming in this sample, a sizeable number of the respondents have the tendency to be obese and also have central obesity. Fruits and vegetables and fibre consumption were generally low.
\end{abstract}

KEY WORDS: Physical activity, dietary intake, anthropometric indices

\section{INTRODUCTION}

Physical activity (PA) levels are decreasing among young people in countries around the world, especially in poor urban areas, and it is estimated that less than one-third are sufficiently active to have a strong impact on their present and future health and well-being (World Health Organization, 2006). Nearly half of those aged 12-21 years are not vigorously active on a regular basis and PA declines dramatically with age during adolescence, with female adolescents being more affected (National Centre for
Chronic Disease Prevention and Health Promotion, 1999). Overweight and obesity are both ranges of weight that are greater than what is generally considered healthy for a given height. The terms also identify ranges of weight that have been shown to increase the likelihood of certain diseases and other health problems (Centre for Disease Control and Prevention, 2006). Body fat distribution is an index of obesity which is significantly associated with morbidity and mortality. Waist-to-hip ratio and waist circumference are other indices associated with 
Physical Activity, Dietary Intake and Anthropometric Indices of a Group of Nigerian University Undergraduates

cardiovascular diseases, premature death, stroke, type 2 diabetes, some cancers and hypertension (Rexrode et al, 2001; Lakka et al, 2002).

It is clear that obesity has a strong genetic component (Bouchard and Perusse, 1993). However, genetics alone may not account for the rapid rise in obesity (Dokken and Tsu-Shuen, 2007) as behavioural differences in diet and exercise habits may be contributory factors (Burke et al, 1992). People worldwide are consuming more foods that are energy-dense, high in sugar and/or saturated fat or excessively salty (Puska et al, 2006). Fast foods are associated with diets that are energy dense and low in essential micronutrients (Bowman and Vinyard, 2004). Frequent fast food consumption, therefore, may contribute to weight gain (Bowman and Vinyard, 2004).

Despite considerable research effort, the nutritional aetiology of obesity remains unclear and controversial, especially with regard to the roles of dietary fat (Willet, 1998; Bray and Popkin, 1998) and carbohydrate (Golay et al, 1996). A recent review of intervention trials found that mean weight loss was greater in studies in which subjects consumed a high-fibre diet than in studies in which subjects consumed a low-fibre diet (Roberts et al, 2002). In those studies, weight loss in subjects that consumed a low-fat, high-fibre diet ( $3.4 \mathrm{~kg}$ over 6 months) was three times that of those that consumed a low-fat diet alone $(1.0 \mathrm{~kg}$ over 6 months) (Roberts et al, 2002). This suggests an additive effect of fat and fibre in weight loss.

In a cross-sectional study, subjects with type 1 diabetes that consumed a diet high in carbohydrates, cereal fibre, and low-glycaemic index foods had a significantly smaller waist circumference and BMI (Toeller et al, 2001). A crossover study among 11 healthy men that both consumed a high-glycaemic index diet and a low-glycemic index diet for five weeks, found that the low-glycaemic index diet led to a decrease in trunk mass and an increase in lean body mass, with no change in body weight (Bouche et al, 2002; Newby et al, 2003).

In spite of the fact that an optimal diet is crucial, daily moderate-intensity PA is also well-established as an important determinant for good health, helping to lower blood pressure, reduce body fat, and improve glucose metabolism (Puska et al, 2006). There is strong scientific evidence that a change in dietary habits and physical activity can reduce the effect of several of the risk factors for chronic diseases (Puska et al, 2006). This study explored the interrelationships between physical activity level, dietary pattern and anthropometric indices among the undergraduate students of the Faculty of Health Sciences in a southeastern Nigerian university.

\section{METHODS}

\section{Subjects}

A cross-sectional study was conducted involving 121 volunteers (57 male and 64 female), aged 19-29 years. They were undergraduates of the Faculty of Health Sciences and Technology of Nnamdi Azikiwe University, Nigeria. The participants were recruited using a non-probability sampling technique.

\section{Physical Activity Assessment}

The self-reported PA levels of participants were assessed using the Long, Last 7 Days International Physical Activity Questionnaire (IPAQ). The IPAQ instrument has acceptable measurement properties for monitoring levels of physical activity among 18 to 65 year old adults in diverse settings. It has a test-retest reliability and criterion validity of $r=0.8$ and $\mathrm{r}=0.3$, respectively (Craig et al, 2003). The questionnaire was scored and interpreted as described in the literature (IPAQ Research Committee, 2005).

\section{Dietary Intake Assessment}

The intake of fat, fruit and vegetable, and fibre was assessed using free assessment tools (NutritionQuest, 2009). This involved participants filling out fat and fruit-vegetablefibre screeners. The filled-out screeners were submitted for analysis online. For the fat screener, the analysis gives the percentage of calorie intake that is fat. Based on this analysis, the fat intake was categorized into either normal (20-35\%) or high (>35\%). For the fruit-vegetable-fibre screener, the analysis had 2 components: fruit and vegetable and fibre. Fruits and vegetables were analysed in terms of servings per day, and based on this, the participants were categorized as having either low ( $<4$ servings) or normal ( $\geq 4$ servings). Also, fibres was analysed in grams per day, and based on this, the participants were categorized as having either low $(<20 \mathrm{~g})$ or normal $(\geq 20 \mathrm{~g})$ intake. The submission of the screeners for analysis required that all the fields were filled out. Participants were therefore requested to fill out any field not applicable to their dietary pattern with the lowest frequency. In other words, a participant who did not have a particular food item in his diet, filled out the lowest frequency against that item instead of omitting it. 


\section{Anthropometric Assessment}

Height and weight were measured using the International Society for Advancement of Kinanthropometry (ISIAK) standards for anthropometric assessments (ISIAK, 2001). Height was measured to the nearest 0.01 decimal place using a height meter (Seca, model 786, Germany). Weight was measured to the nearest 0.01 decimal place using a bathroom scale (Hana, model BR9011; 120 x $0.01 \mathrm{~kg}$, China). The BMIs of the participants were calculated from their respective heights and weights using the relation: weight/height. ${ }^{2}$ From these BMI values, normal weight, overweight, and obesity were determined using the World Health Organization (WHO) criteria for body weight determination (WHO, 2000).

Waist circumference (WC) and hip circumference were measured at the level of the umbilicus and greater trochanter, using an inelastible tape measure, and the waisthip ratio $(\mathrm{W} / \mathrm{H})$ was calculated from the two values and was categorized using the World Health Organization criteria (WHO, 2000). The measurement was recorded to the nearest $0.1 \mathrm{~cm}$. Waist-hip ratio $<0.95$ was categorized as normal and $\geq 0.95$ as undesirable for men. For women, $\mathrm{W} / \mathrm{H}<0.85$ was categorized as normal, while $\geq 0.85$ was categorized as undesirable.

\section{Data Analysis}

The data obtained was presented using bar charts, frequency and proportion. Chi-square was used to analyse the difference in these categorical variables: fat intake, fruit and vegetable, fibre intake, body mass index, waist circumference, waist-hip ratio, and the physical activity level of participants. Spearman's rank order correlation was used to determine the relationship between dietary intake, anthropometric indices, and the physical activity level of participants.

\section{RESULTS}

More of the participants $(52.9 \%)$ were female. The age of the respondents ranged 19 to 29 , with a mean age of 22.34 \pm 1.88 years (table 1 ). The proportions of the male and the female participants with normal weight were $79.6 \%$ and
$82.4 \%$, respectively (figure 1 ). About $2 \%$ of the female participants were underweight as opposed to none among the male participants. More of the male participants $(18.5 \%)$ than the females $(11.8 \%)$ had the tendency to be overweight. More females $(4.4 \%)$, however, tended to be obese than the males $(1.9 \%)$. Fewer males $(11 \%)$ than females $(17.6 \%)$ reported low physical activity level (figure 2 ). Fewer females $(44.1 \%)$ than males $(55.6 \%)$, however, reported high physical activity level (figure 2). Fewer males tended to have undesirable waist circumference and waisthip ratio than the females $(5.7 \% \& 7.7 \%$, respectively for male; $16.2 \%$ and $41.2 \%$, respectively for female). The fat intake level of males $(24.1 \%)$ tended to be lower than that of females $(30.9 \%$ ) (table 2). About $87 \%$ of the male participants ate low amounts of fruits and vegetables as against about $79.4 \%$ for the female participants (table 2). About $57 \%$ of the male participants ate low amounts of fibre as opposed to about $89.7 \%$ for the females (table 2). The females had a higher waist-hip ratio than the males, while the males consumed more fibre (table 3). Fat intake was found to correlate very significantly $(\mathrm{P}<0.05)$ with $\mathrm{WC}$, fibre intake correlated very significantly with $\mathrm{WC}$ and waist-hip ratio, while PA correlated significantly with BMI and WC (table 4).

\section{DISCUSSION}

This study explored the interrelationships among physical activity level, dietary pattern and anthropometric indices among undergraduate students of the Faculty of Health Sciences in a university in southeastern Nigeria. The study shows that a vast majority of the participants had normal anthropometry, which is in consonance with the finding that an almost equal proportion of them consumed normal levels of fat. This proportionality in normalcy of body anthropometry and fat consumption could be explained in light of the fact that the high energy density of fat may promote excess energy intake (Rolls, 2000) and total dietary fat has been directly associated with adiposity (Tucker et al, 1997). Other authors (Slattery, 1992; Larson et al, 1996), however, did not find any association between level of fat consumption and body anthropometry.

Table 1. Physical and anthropometric characteristics of the participants

\begin{tabular}{|c|c|c|c|c|c|c|}
\hline & Age (years) & BMI $\left(\mathrm{kg} / \mathrm{m}^{2}\right)$ & $\mathrm{WC}(\mathrm{cm})$ & $\mathrm{W} / \mathrm{H}$ & Age (years) & BMI $\left(\mathrm{kg} / \mathrm{m}^{2}\right)$ \\
\hline & $\mathrm{X} \pm \mathrm{S} . \mathrm{D}$ & $X \pm S . D$ & $X \pm S . D$ & $X \pm S . D$ & $X \pm S . D$ & $X \pm S . D$ \\
\hline Male & $22.9 \pm 1.88$ & $23.45 \pm 2.69$ & $76.32 \pm 12.02$ & $0.83 \pm 0.04$ & $19.84 \pm 3.98$ & $5187.922 \pm 3439.849$ \\
\hline Female & $21.84 \pm 1.76$ & $22.85 \pm 2.92$ & $74.66 \pm 7.10$ & $0.80 \pm 0.05$ & $15.05 \pm 3.51$ & $4149.968 \pm 3060.450$ \\
\hline Overall & $22.34 \pm 1.88$ & $23.13 \pm 2.82$ & $75.44 \pm 9.23$ & $0.81 \pm 0.05$ & $17.28 \pm 4.43$ & $4618.425 \pm 3263.874$ \\
\hline
\end{tabular}


Physical Activity, Dietary Intake and Anthropometric Indices of a Group of Nigerian University Undergraduates

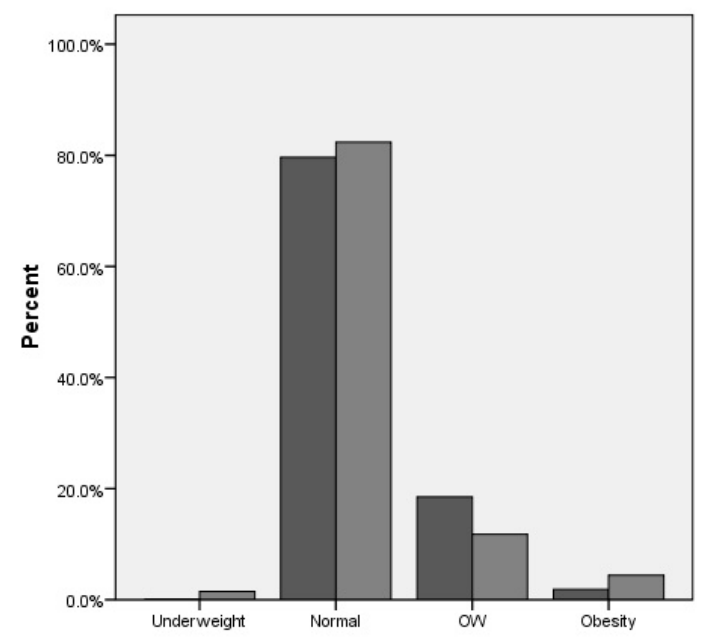

Table 3. Comparison of distribution of anthropometric, dietary and physical activity characteristics between male and female participants using Chi-square

\begin{tabular}{ll}
\hline Characteristic & P-value $(95 \% \mathrm{Cl})$ \\
\hline Body mass index & $0.388(0.283-0.454)$ \\
Waist circumference & $0.213(0.140-0.286)$ \\
Waist-hip circumference & $0.000^{*}$ \\
Fat intake & $0.672(0.589-0.755)$ \\
Fruit and vegetable intake & $0.664(0.580-0.748)$ \\
Fibre intake & $0.000 *$ \\
Physical activity level & 0.254 \\
\hline
\end{tabular}

Figure 1. Distribution of body mass index of participants.

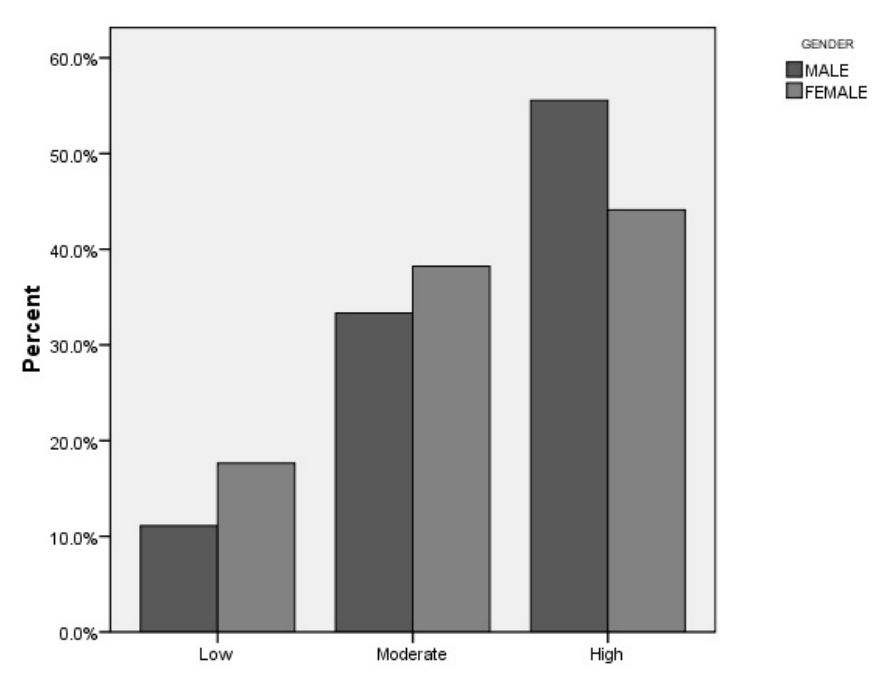

Figure 2. Distribution of physical activity level of participants.

Table 2. Distribution of anthropometric and dietary characteristics of participants by gender

\begin{tabular}{lcccc}
\hline & \multicolumn{2}{c}{ Male } & \multicolumn{2}{c}{ Female } \\
\cline { 2 - 4 } & $\begin{array}{c}\text { Normal } \\
\mathrm{n}(\%)\end{array}$ & $\begin{array}{c}\text { Undesirable } \\
\mathrm{n}(\%)\end{array}$ & $\begin{array}{c}\text { Normal } \\
\mathrm{n}(\%)\end{array}$ & $\begin{array}{c}\text { Undesirable } \\
\mathrm{n}(\%)\end{array}$ \\
\hline $\begin{array}{l}\text { Waist } \\
\text { circumference }\end{array}$ & $50(94.3)$ & $3(5.7)$ & $57(83.8)$ & $11(16.2)$ \\
$\begin{array}{l}\text { Waist-hip } \\
\text { circumference }\end{array}$ & $48(92.3)$ & $4(7.7)$ & $40(58.8)$ & $28(41.2)$ \\
$\begin{array}{l}\text { Fat intake } \\
\begin{array}{l}\text { Fruit and } \\
\text { vegetable }\end{array}\end{array}$ & $41(75.9)$ & $13(24.1)$ & $47(69.1)$ & $21(30.9)$ \\
intake & $7(13.0)$ & $47(87.0)$ & $14(20.6)$ & $54(79.4)$ \\
Fibre intake & $23(42.6)$ & $31(57.4)$ & $7(10.3)$ & $61(89.7)$ \\
\hline
\end{tabular}

Table 4. Correlation of dietary intake with anthropometric and physical activity variables using Spearman's rank order and Pearson correlation

\begin{tabular}{|c|c|c|c|}
\hline \multirow{2}{*}{$\begin{array}{l}\text { Dietary intake } \\
\& \text { physical } \\
\text { activity }\end{array}$} & \multicolumn{3}{|c|}{ Anthropometric variables } \\
\hline & $\begin{array}{l}\text { Body mass } \\
\text { index }\end{array}$ & $\begin{array}{c}\text { Waist } \\
\text { circumference }\end{array}$ & Waist-hip ratio \\
\hline Fat & 0.041 & $-0.188 * *$ & -0.028 \\
\hline $\begin{array}{l}\text { Fruit and } \\
\text { vegetable }\end{array}$ & 0.012 & 0.098 & 0.027 \\
\hline Fibre & -0.043 & -0.167 & $-0.260 * *$ \\
\hline $\begin{array}{l}\text { Physical } \\
\text { activity }\end{array}$ & $0.152 *$ & $0.118^{*}$ & 0.016 \\
\hline
\end{tabular}

In contrast to the proportion of participants who consumed normal amounts of fat in this study, the proportions of those who consumed adequate amounts of fruits and vegetables (FV), as well as fibre were in the minority. The latter findings, in relation to the findings for body anthropometry, are antitheses, and this is because dietary fibre promotes satiety (Pereira and Ludwig, 2001), through decreased gastric emptying, increased colonic transit, and decreased insulin response (Kimm, 1995). In addition, it may protect against excessive weight gain via effects that could be mediated by, and/or independent of glycaemic index (Ludwig et al, 1999). Furthermore, fruits and non-starchy vegetables may protect against excessive weight gain (Newby et al, 2003; He et al, 2004), because of their low energy density, high fibre content, and low glycemic index. This low glycemic load evokes a decreased insulin response and, therefore, decreases hunger and eventual energy intake (Ludwig, 2002). A recent review of 
intervention trials found that mean weight loss was greater in studies in which subjects consumed a high-fibre diet than in studies in which subjects consumed a low-fibre diet (Roberts et al, 2002). It is interesting to find that in this sample, where only a minority consumed adequate amounts of fruits and vegetables, as well as fibres, an overwhelming majority had desirable body anthropometry. In view of these unusual trends, the confounding factor in this study could be found in either the physical activity level and/or the amount of fat consumed.

The normal fat consumption level observed in the participants could have a favourable effect on the dependent variables (body anthropometry). Moreover, about one in two participants were highly physically active; also close to that ratio engaged in moderate level of physical activity. Considering these levels of physical performance, one may expect a favourable effect on body anthropometry independent of the amount of FV and fibre consumed. This is in view of the findings in previous studies establishing the crucial role of physical activity and energy expenditure in obesity prevention ( $\mathrm{Hu}$ et al, 2003). Furthermore, considering the interactions of the beneficial effects of FV and fibre on body anthropometry, the favourable effect of physical activity level could be greatly enhanced. However in spite of this possibility, participants in the increased FV group are more likely to significantly reduce the probability of being overweight than those in the only reduced fat and sugar group (Epstein et al, 2001). Singh et al (1994) found that patients with myocardial infarction on a low-energy, fruit and vegetable enriched diet for 6 months had a great reduction in central obesity.

More males than females consumed adequate amounts of fibre and were also found to have desirable waist-hip ratio. These findings further corroborate the reports that higher fibre intake fosters desirable body composition. Fibre consumption was found to correlate negatively with $\mathrm{W} / \mathrm{H}$ and $\mathrm{WC}$, but not with BMI. Fat consumption correlated positively with only $\mathrm{WC}$, while PA correlated negatively with BMI and WC. These findings suggest that waist circumference is an adiposity index that is easily modulated by dietary intake and PA (Koh-Banerjee et al, 2003). From these findings, it could be inferred that PA, fibre and fat consumption play a role in controlling specific anthropometric indices. These findings are somewhat similar to those of Afolabi et al (2004), who found that energy intake positively correlates with BMI. These studies are, however, different in terms of age range and mode of assessment of dietary intake. Lahti-koski et al (2002) reported an inverse association between BMI and PA in women. In addition, a previous study (Gutierrez-Fisac et al, 2002) found that BMI varied significantly by leisure-time PA and not by work-related PA. Many studies found that people who are physically active on a regular basis are less likely to gain weight (Schmitz et al, 2000; Drøyvold et al, 2004; Kimm et al, 2005; Besson et al, 2009).

The findings in this study cannot be generalized to children and adolescents, as well as middle-aged adults. The findings are not based on cause and effect, but are merely descriptive and correlational. Intervention trials are strongly encouraged, as they would provide more definitive findings. Also, the sample size for this study is small. A larger sample size is suggested to validate the findings in this study.

Inadequate consumption of FV has been associated with obesity-related morbidities such as cardiovascular diseases (Bazzano et al, 2002) and diabetes (Ford and Mokdad, 2001). In view of this, reducing obesity and overweight should be considered a major public health and clinical challenge. Therefore, in addition to the development of national and community-based strategies and initiatives to encourage adequate consumption of $\mathrm{FV}$, it is important for dietitians and clinicians to counsel individuals on lifestyle and behavioural modifications (Stopt et al, 2003) in order to acquire present and future health benefits.

\section{References}

Afolabi, W.A.O., A.A. Addo and M.A. Shonibare. 2004. Activity pattern, energy intake and obesity among Nigerian urban market women. International Journal of Food Science and Nutrition 55(2): 85-90.

Bazzano, LA., J. He, L.G. Ogden, C.M. Loria, S. Vupputuri, L. Myers and P.K. Whelton. 2002. Fruit and vegetable intake and risk of cardiovascular disease in US adults: The first National Health and Nutrition Examination SurveyEpidemiological Follow-up Study. American Journal of Clinical Nutrition 76: 93-99.

Besson, H., U. Ekelund and U. Ekelund. 2009: A cross-sectional analysis of physical activity and obesity indicators in European participants of the EPIC-PANACEA study. International Journal of Obesity 33: 497-509.

Bouchard, C. and L. Perusse. 1993. Genetics of obesity. Annual Review of Nutrition; 3: 337-354.

Bouche, C., S.W. Rizkalla, J. Luo, H. Vidal, A. Veronese, N. Pacher, C. Fouquet, V. Lang and G. Slama. 2002. Five-week, low-glycemic index diet decreases total fat mass and improves plasma lipid profile in moderately overweight non-diabetic men. Diabetes Care. 25:822-8.

Bowman, S.A. and B.T. Vinyard. 2004. Fast food consumption of US adults: Impact on energy and nutrients intakes and 
Physical Activity, Dietary Intake and Anthropometric Indices of a Group of Nigerian University Undergraduates

overweight status. Journal of the American College of Nutrition 23(2): 163-168.

Bray, G.A. and B.M. Popkin. 1998. Dietary fat intake does affect obesity. American Journal of Clinical Nutrition 68:1157-73.

Burke, G.L., P.J. Savage, T.A. Manolio, J.M. Sprafka, L.E. Wagenknecht, S. Sidney, L.L. Perkins, K. Liu and D.R. Jacobs. 1992. Correlates of obesity in young black and white women: The CARDIA Study. American Journal of Public Health. 82, 1621-1625.

Centre for Disease Control and Prevention. 2006. Physical activity resources for health professionals: introduction.

Craig, C.L., A.L. Marshall, M. Sjostrom, A.E. Bauman, M.L. Booth, B.E. Ainsworth, M. Pratt, U. Ekelund, A. Yngve, J.F. Sallis and P. Oja. 2003. International physical activity questionnaire: 12-country reliability and validity. Med Sci Sports Exerc 35(8): 1381-95.

Dokken BB and T-S Tsao. 2007. The physiology of body weight regulation: Are we too efficient for our own good. Diabetes Spectrum 31: 166-170.

Drøyvold, W.B., J. Holmen, K. Midthjell, S. Lydersen and The Nord-Trøndelag Health Study (HUNT). 2004. BMI change and leisure time physical activity (LTPA): An 11-y follow-up study in apparently healthy men aged 20-69 y with normal weight at baseline. International Journal of Obesity 28(3): 410-17.

Epstein, L.H., C.C. Gordy, H.A. Raynor, M. Beddome, C.K. Kilanowski and R. Paluch. 2001. Increasing fruit and vegetable intake and decreasing fat and sugar intake in families at risk for childhood obesity. Obesity Research 9: 171-178.

Ford, E.S. and A.H. Mokdad. 2001. Fruit and vegetable consumption and diabetes mellitus incidence among US adults. Preventive Medicine. 32: 33-39.

Giazzanga, J.M. and T.L. Burns. 1993. Relationship between diet composition and body fatness, with adjustment for resting energy expenditure and physical activity, in adolescent children. American Journal of Clinical Nutrition 58: 21-28.

Golay, A., A.F. Allaz, Y. Morel, N. de Tonnac, S. Tankova and G. Reaven. 1996. Similar weight loss with low- or highcarbohydrate diets. American Journal of Clinical Nutrition 63:174-8.

Gutierrez-Fisac, J.L., P. Guallar-Castillion, L. Diez-Gana, E.L.Garcia, J.R. Banegas and J.R. Artalejo. 2002. Workrelated physical activity is not associated with body mass index and obesity. Obesity Research 10(4): 270-76 .

He, K., F.B. Hu, G.A. Colditz, J.E. Manson, W.C. Willett and S. Liu. 2004. Changes in intake of fruits and vegetables in relation to risk of obesity and weight gain among middle-aged women. International Journal of Obesity 28, 1569-1574.

Hu, F.B., T.Y. Li TY, G.A. Colditz, W.C. Willett and J.E. Manson. 2003. Television watching and other sedentary behaviours in relation to risk of obesity and type 2 diabetes mellitus in women. Journal of American Medical Association 289: 1785-1791.

International Society for the Advancement in Kinanthropometry (ISIAK). 2001. International Standard for Anthropometric Assessment. Unerdale, SA, Australia: ISIAK, pp. 1-133.
IPAQ Research Committee. 2005. Guidelines for the Data Processing and Analysis of the International Physical Activity Questionnaire. www.ipaq.ki.se. Accessed on 15/05/2007.

Kimm, S.Y. 1995. The role of dietary fiber in the development and treatment of childhood obesity. Pediatrics 96:1010-4.

Kimm, S.Y.S., N.W. Glynn, E. Obarzanek, A.M. Kriska, S.R. Daniels, B.A. Barton and K. Liu. 2005. Relation between the changes in physical activity and body-mass index during adolescence: a multicentre longitudinal study. Lancet 366 (9482): 301-07.

Koh-Banarjee, P., N-F. Chu, D. Spiegelman, F.B. Rosner, G. Colditz, W. Willet and E. Rimm. 2003. Prospective study of the association of changes in dietary intake, physical activity, alcohol consumption, and smoking with 9-year gain in waist circumference among 16587 US men. American Journal of Clinical Nutrition 78(4): 719-727.

Lahti-Koski. M., P. Pietnen, M. Heliovaara and E. Vartiainem. 2002. Associations of body mass index and obesity with physical activity, food choices, alcohol intake and smoking in the 1982-1997 FINRISK Studies. American Journal of Clinical Nutrition 75: 809-17.

Lakka, H.M., T.A. Lakka, J. Tuomilehto and J.T. Salonen . 2002. Abdominal obesity is associated with increased risk of acute coronary events in men. European Heart Journal 23:706-13.

Larson, D.E., G.R. Hunter, M.J. Williams, T. Kekes-Szabo, I. Nyikos M.I. Goran. 1996. Dietary fat in relation to body fat and intra-abdominal adipose tissue: A cross-sectional analysis. American Journal of Clinical of Nutrition 64: 677-684.

Ludwig, D.S. 2002. Dietary glycemic index and obesity. Journal of Nutrition 130: 280S-283S.

Ludwig, D.S., M.A. Preira, C.H. Kroenke, J.E. Hilner, L.V. Horn, M.L. Slattery and D.R. Jacobs. 1999. Dietary fibre, weight gain and cardiovascular disease risk factors in young adults; The CARDIA STUDY. Journal of American Medical Association 282: 1539-1546

National Centre for Chronic Disease Prevention and Health Promotion. 1999. Physical Activity and Health-at-a-glance; A Report of the Surgeon General; Physical Activity and Health.

National Heart, Lung, and Blood Institute. National Institute of Diabetes and Digestive and Kidney Diseases. 1998. Clinical Guidelines on the Identification, Evaluation and Treatment of Overweight and Obesity in Adults. Bethesda: National Institute of Health, NIH Publication No. $09-4083$.

Newby, P.K., D. Muller, J. Hallfrisch, N. Qiao, R. Andres and K.L. Tucker. 2003. Dietary patterns and changes in body mass index and waist circumference in adults. American Journal of Clinical Nutrition 77: 1417-1425.

NutritionQuest. (2009). Free assessment tools for individuals. www.nutritionquest.com/free tools/fruit-vegetable-fiberscreen. Accessed on 25/03/07.

Pereira, M.A. and D.S. Ludwig. 2001. Dietary fibre and bodyweight regulation: Observations and mechanisms. Pediatrics Clinics of North America 48: 969-980.

Puska, P., A. Waxman and D. Porter. 2006. World Health Organization Global Safety on Diet, Physical Activity and 
Health. www.who.int/dietphysicalactivity/strategy/.../strateg y...eng...web.p.. Accessed on 27/07/2012.

Rexrode, K.M., J.E. Buring and J.E. Manson. 2001. Abdominal and total adiposity and risk of coronary heart disease in men. International Journal of Obesity Related Metabolic Disorder 25:1047-56.

Roberts, S.B., M.A. McCrory and E. Saltzman. 2002. The influence of dietary composition on energy intake and body weight. Journal of American College of Nutrition 21:140S-5S.

Rolls, B.J. 2000. The role of energy density in the overconsumption of fat. Journal of Nutrition. 130: 2683-2713

Schmitz, K.H., D.R. Jacobs, A.S. Leon, P.J. Schreiner and B. Sternfeld. 2000. Physical activity and body weight: Associations over ten years in the CARDIA study. Coronary Artery Risk Development in Young Adults. International Journal of Obesity and Related Metabolic Disorders 24 (11): 1475-87.

Shevitz, A., C. Wanke, J. Falutz and D. Kotler. 2001. Clinical perspectives on HIV-associated lipo-dystrophy syndrome: An update. AIDS 2001; 15:1917-30.

Singh. R.B., M.A. Niaz and S. Ghosh. 1994. Effect on central obesity and associated disturbances of low-energy, fruits- and vegetable-enriched prudent diet in north Indians. Postgraduate Medical Journal. 70: 895-900.

Slattery, M.L., A. McDonald, D.E. Bild, B.J. Caan, JE., Hilner, D.R. Jacobs and K. Liu. 1992. Association of body fat and its distribution with dietary intake, physical activity, alcohol, and smoking in blacks and whites. American Journal of Clinical Nutrition. 55:943-949

Steptoe, A., L. Perkins-Porras, C. McKay, E. Rink, S. Hilton and F.P. Cappuccio. 2003. Behavioural counselling to increase consumption of fruit and vegetables in low income adults: Randomized trial. British Medical Journal 326: 855-860.

Toeller, M., A.E. Buyken, G. Heitkamp, G. Cathelineau, B. Ferriss and G. Michel. 2001. Nutrient intakes as predictors of body weight in European people with type 1 diabetes. International Journal of Obesity Related Metabolic Disorder 25:1815-22.

Tucker, L.A., G.T. Selijaas and R.L. Hager. 1997. Body fat percentage of children varies according to their diet composition. Journal of American Dietary Association 97:981986.

Willett, W.C. 1998. Is dietary fat a major determinant of body fat? American Journal of Clinical Nutrition 67(suppl):556-62S.

World Health Organization (2000): Obesity: preventing and managing the global epidemic. Report of a WHO Consultation. WHO Technical Report Series 894. Geneva. www.whqlibdoc.who.int/trs/WHO_TRS_894.pdf accessed on 27/07/2012 